\title{
RESEARCH
}

Open Access

\section{Alterations of mesenchymal stromal cells in cerebrospinal fluid: insights from transcriptomics and an ALS clinical trial}

Ashley A. Krull', Deborah O. Setter ${ }^{1}$, Tania F. Gendron², Sybil C. L. Hrstka ${ }^{1}$, Michael J. Polzin', Joseph Hart ${ }^{1}$, Amel Dudakovic ${ }^{3}$, Nicolas N. Madigan ${ }^{1}$, Allan B. Dietz ${ }^{4}$, Anthony J. Windebank1, Andre J. van Wijnen ${ }^{3}$ and Nathan P. Staff ${ }^{1 *}$ (D)

\begin{abstract}
Background: Mesenchymal stromal cells (MSCs) have been studied with increasing intensity as clinicians and researchers strive to understand the ability of MSCs to modulate disease progression and promote tissue regeneration. As MSCs are used for diverse applications, it is important to appreciate how specific physiological environments may stimulate changes that alter the phenotype of the cells. One need for neuroregenerative applications is to characterize the spectrum of MSC responses to the cerebrospinal fluid (CSF) environment after their injection into the intrathecal space. Mechanistic understanding of cellular biology in response to the CSF environment may predict the ability of MSCs to promote injury repair or provide neuroprotection in neurodegenerative diseases.
\end{abstract}

Methods: In this study, we characterized changes in morphology, metabolism, and gene expression occurring in human adipose-derived MSCs cultured in human (hCSF) or artificial CSF (aCSF) as well as examined relevant protein levels in the CSF of subjects treated with MSCs for amyotrophic lateral sclerosis (ALS).

Results: Our results demonstrated that, under intrathecal-like conditions, MSCs retained their morphology, though they became quiescent. Large-scale transcriptomic analysis of MSCs revealed a distinct gene expression profile for cells cultured in aCSF. The aCSF culture environment induced expression of genes related to angiogenesis and immunomodulation. In addition, MSCs in aCSF expressed genes encoding nutritional growth factors to expression levels at or above those of control cells. Furthermore, we observed a dose-dependent increase in growth factors and immunomodulatory cytokines in CSF from subjects with ALS treated intrathecally with autologous MSCs.

Conclusions: Overall, our results suggest that MSCs injected into the intrathecal space in ongoing clinical trials remain viable and may provide a therapeutic benefit to patients.

Keywords: Mesenchymal stromal cell, Gene expression, Neuroinflammation, Growth factors, Cerebrospinal fluid, Amyotrophic lateral sclerosis, Human studies

\footnotetext{
* Correspondence: Staff.Nathan@mayo.edu

'Department of Neurology, Mayo Clinic, 200 First St. SW, Rochester, MN 55905, USA

Full list of author information is available at the end of the article
}

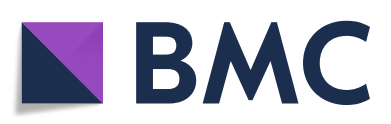

(- The Author(s). 2021 Open Access This article is licensed under a Creative Commons Attribution 4.0 International License, which permits use, sharing, adaptation, distribution and reproduction in any medium or format, as long as you give appropriate credit to the original author(s) and the source, provide a link to the Creative Commons licence, and indicate if changes were made. The images or other third party material in this article are included in the article's Creative Commons licence, unless indicated otherwise in a credit line to the material. If material is not included in the article's Creative Commons licence and your intended use is not permitted by statutory regulation or exceeds the permitted use, you will need to obtain permission directly from the copyright holder. To view a copy of this licence, visit http://creativecommons.org/licenses/by/4.0/. The Creative Commons Public Domain Dedication waiver (http://creativecommons.org/publicdomain/zero/1.0/) applies to the data made available in this article, unless otherwise stated in a credit line to the data. 


\section{Introduction}

Mesenchymal stromal cells (MSCs) are increasingly being employed in clinical trials to treat neurodegenerative diseases despite a lack of mechanistic investigations into the phenotypes of MSCs when injected into the central nervous system (CNS) compartment. For many current trials for neurological diseases, MSCs are extracted from adipose tissues or bone marrow, expanded in vitro, and then injected into the intrathecal cerebrospinal fluid (CSF) of the CNS to bypass the blood-brain barrier. The hypothesis, based on pre-clinical in vitro and animal models, is that MSCs will secrete factors that have a therapeutic effect on neurons and the surrounding microenvironment. MSC-based therapy is attractive because most neurodegenerative diseases involve multifaceted pathologies, and MSCs have been shown to favorably modulate the majority of these pathological processes. However, pre-clinical models often recapitulate neither the intrathecal microenvironment nor the preparation of MSCs that would be administered to a clinical trial patient, hampering responsible translation of MSCs into clinical use.

Intrathecal CSF represents a uniquely challenging environment for cultured MSCs: it has a lower partial pressure of oxygen than media in culture conditions $(\sim 70$ $80 \mathrm{mmHg}$ in CSF) [1], undergoes age- and diseaserelated changes in protein composition [2-4], and contains less protein compared to plasma, with CSF containing primarily albumin and brain-derived factors [5]. When MSCs are cultured in vitro, cells are grown at normoxia and the growth media must be supplemented with nutrient-rich human platelet lysate (hPL) to support healthy proliferation prior to their harvest and implantation. When cultured without serum or hPL, or in hypoxic conditions, MSCs have been shown to rapidly undergo apoptosis and risk chromosomal instability [68]. However, previous studies-albeit utilizing diluted CSF formulations-have shown that MSCs can remain viable and increase the presence of nutritional factors within CSF [9-11]. So how are researchers and clinicians to harmonize this data to balance the risks with the purported benefits of MSC therapy?

In addition to the above-mentioned weaknesses of pre-clinical models, they often also fail to account for the preparation of MSCs for clinical use, which has the potential to drastically impact the phenotype of MSCs. The field of cell therapy is becoming increasingly cognizant of how culture conditions affect MSCs. Understandably, most preclinical research to date has been conducted using research-grade reagents, such as media supplemented with fetal bovine serum, that are not permitted for cells destined for human use. This distinction is important to note as numerous studies demonstrated that MSCs grown in compliance with current good manufacturing practices (GMP) versus nonGMP conditions (and even within varying GMPcompliant conditions) display disparate phenotypes characterized by different proliferation rates, differentiation potentials, and immunomodulatory potentials [12-15]. At present, it is unclear how in vitro manufacturing conditions ultimately influence the response of MSCs to the CSF environment. Furthermore, how the CSF microenvironment, with its lower oxygen and nutrient levels, impacts MSCs cultured for clinical use is also unknown.

To address these gaps in understanding, and to guide stakeholders in MSC-based treatment of neurodegenerative diseases, we aimed to characterize the morphological, metabolic, and transcriptomic changes observed when MSCs are incubated in undiluted human (hCSF) or artificial CSF (aCSF) as compared to control media (CM; containing GMP-grade hPL) and platelet lysatefree (PLF) media. We hypothesized that the phenotype of MSCs cultured in undiluted CSF formulations would mimic that of MSCs cultured in conditions devoid of platelet lysate, which are known to be stressful for MSCs. To extend prior work and to most accurately reflect the clinical application, our studies emphasized the use of clinical-grade MSCs cultured in GMP-grade reagents to recapitulate the phenotype of cells that are currently used to treat patients [16-18].

To supplement our in vitro results, we undertook a secondary set of experiments in which we analyzed CSF collected from subjects in a phase I clinical trial at the Mayo Clinic investigating the use of intrathecal MSCs to treat amyotrophic lateral sclerosis (ALS) [17], a neurodegenerative disorder that leads to a progressive and fatal paralysis. These secondary experiments were designed to examine the protein levels of therapeutically-relevant growth and immunomodulatory factors within the CSF of patients treated with MSCs for additional evidence to support the potential therapeutic mechanism of action of MSCs within the intrathecal space.

\section{Materials and methods}

\section{Mesenchymal stromal cells and cerebrospinal fluid}

With approval from the Mayo Clinic Institutional Review Board (IRB), MSCs were obtained from four consenting, healthy patients who underwent elective removal of subcutaneous adipose tissue either by lipoaspiration [male/41 years (M1), female/32 years (F1), male/ 54 years (M2)] or by surgical biopsy [a female (F2) bariatric patient who donated cells as medical waste so age was not collected]. Samples were processed to isolate and expand MSCs as previously described [7, 19, 20]. Cells were stored in liquid nitrogen until use. All patient information was kept confidential and all identifiers removed prior to any studies. 
hCSF that otherwise would be disposed as medical waste was obtained from consenting patients treated with lumbar puncture in the Hydrocephalus Clinic at the Mayo Clinic with approval from the Mayo Clinic IRB.

\section{Solutions}

CM used for studies consisted of Advanced Minimal Essential Medium (MEM) standard culture medium with 5\% PLTmax (platelet lysate solution, Mill Creek Life Sciences), $2 \mathrm{U} / \mathrm{mL}$ heparin (hospital pharmacy), $2 \mathrm{mML}$ glutamine (Invitrogen), and antibiotics $(100 \mathrm{U} / \mathrm{ml}$ penicillin, $100 \mathrm{~g} / \mathrm{ml}$ streptomycin). The PLF media was made using Advanced MEM with $2 \mathrm{mM} \mathrm{L}$-glutamine and antibiotics. The aCSF formulation comprised the following: distilled water with $\mathrm{NaCl}(124 \mathrm{mM}), \mathrm{KCl}(2.5 \mathrm{mM})$, $\mathrm{NaHCO}_{3}(26 \mathrm{mM}), \mathrm{NaH}_{2} \mathrm{PO}_{4}-\mathrm{H}_{2} \mathrm{O}(1.25 \mathrm{mM}), \mathrm{MgSO}_{4}$ (1 mM), $\mathrm{CaCl}_{2}(2 \mathrm{mM})$, D-glucose $(60 \mathrm{mg} / \mathrm{dL})$, and human albumin $(30 \mathrm{mg} / \mathrm{dL})$. The aCSF had a pH of 7.4 and was warmed along with the other solutions before use.

\section{Immunocytochemistry on MSCs cultured in human CSF} MSCs were seeded in CM at 3000 cells $/ \mathrm{cm}^{2}$ in 6-well plates for $24 \mathrm{~h}$ on glass coverslips prior to introduction of fresh CM, PLF media, or hCSF for 24-48 h. Upon removal of the media, cells were stained with pre-warmed $100 \mathrm{nM}$ MitoTracker CMX-Ros solution (Invitrogen, Carlsbad, CA) for $20 \mathrm{~min}$ at $37^{\circ} \mathrm{C}$. Cells were then fixed for $10 \mathrm{~min}$ in a pre-warmed solution of $4 \%$ paraformaldehyde in Dulbecco's phosphate buffer solution (D-PBS). Following fixation, cells were washed $3 \mathrm{x}$ for $5 \mathrm{~min}$ in $1 \mathrm{x}$ D-PBS, permeabilized for $10 \mathrm{~min}$ with phosphate buffered solution with Triton X-100 (PBS-T-0.1\% Triton $\mathrm{X}-100$ in $1 \mathrm{x}$ PBS), and washed again $3 \mathrm{x}$ for $5 \mathrm{~min}$ in $\mathrm{D}-$ PBS. Cells were blocked for $30 \mathrm{~min}$ with $1 \%$ bovine serum albumin in 1x D-PBS. Cells were incubated for 60 min with Alexa Fluor 488 phalloidin (1:100, Invitrogen, Carlsbad, CA). After washing in 1x D-PBS and removal of excess liquid, the cover slips were mounted onto slides using ProLong Gold antifade reagent with DAPI (Invitrogen, Carlsbad, CA) and left to cure overnight. Slides were imaged with an AxioScope fluorescent microscope at $\times 40$ magnification.

\section{Metabolic activity of MSCs in aCSF}

MSCs were seeded in CM at 2500 cells $/ \mathrm{cm}^{2}$ in 12-well plates and grown to about $80 \%$ confluency prior to introduction of fresh CM, PLF media, or aCSF for 24$96 \mathrm{~h}$. At each time point, culture solutions were collected and cell viability analyzed using an MTS assay following the manufacturer's instructions (Promega, Madison, WI). Absorbance of each sample was read at $490 \mathrm{~nm}$ using a plate reader and corrected using absorbance values of empty control wells. Metabolic activity for PLF media- and aCSF-treated cells was assessed in comparison to the absorbance of wells containing control CM-treated cells.

\section{Transcriptomic analyses}

MSCs were seeded with about 3000 cells $/ \mathrm{cm}^{2}$ in 6 -well plates and monitored until approximately $80 \%$ confluent. Cells were incubated in with fresh CM, PLF media, or aCSF for 24 or $48 \mathrm{~h}$ before harvesting. Cells from each line were plated in three replicate wells per condition per time point to yield 18 wells total per line -6 treated with CM, 6 treated with PLF media, 6 treated with aCSF-with half the wells treated for $24 \mathrm{~h}$ and half treated for $48 \mathrm{~h}$. Total RNA was isolated per the manufacturer's instructions using the miRNeasy Mini Plus Kit (Qiagen, Germantown, MD). RNA libraries were prepared according to the manufacturer's instructions for the TruSeq RNA Sample Prep Kit v2 (Illumina, San Diego, CA) that uses oligo dT magnetic beads to enrich poly-A mRNA. Polymerase chain reaction (PCR) was used to enrich the resulting cDNA fragments using Illumina TruSeq PCR primers. The concentration and size distribution of the completed library was determined using a Fragment Analyzer (AATI, Ankeny, IA) and Qubit fluorometry (Invitrogen, Carlsbad, CA). The cDNA library was sequenced at 30-50 million fragment reads per sample following Illumina's standard protocol using the Illumina cBot and HiSeq 3000/4000 PE Cluster Kit. The flow cells were sequenced as $100 \mathrm{X} 2$ pairedend reads on an Illumina HiSeq 4000 using the HiSeq 3000/4000 sequencing kit and HD 3.4.0.38 collection software. Base-calling was performed using Illumina's RTA version 2.7.7. In order to validate the transcriptomic PCR data, an independent set of experiments were performed using conventional real-time qPCR and were confirmatory (Supplemental Figure 3).

\section{Bioinformatics analysis}

Gene expression counts were obtained using the MAPRSeq v.1.2.1.5 workflow [21], the Mayo Bioinformatics Core pipeline. MAP-RSeq consists of alignment with TopHat 2.0.6 [22] against the human hg19 genome build and gene counts with the HTSeq software (http://wwwhuber.embl.de/users/anders/HTSeq/doc/overview.html). Gene annotation files were obtained from Illumina (https://support.illumina.com/sequencing/sequencing_ software/igenome.html). Normalized gene counts were obtained from MAP-RSeq, where expression levels for each gene were normalized to one million reads and corrected for gene length (fragments per kilobase pair per million mapped reads [FPKM]). For heatmap and principal component analysis (PCA) visualizations, significant genes were selected based on an average FPKM $>1$, a log-fold-change $>$ or $<$ absolute value of 1 , and a $p$ value $<0.05$, when comparing aCSF-treated to PLF media- 
treated MSCs. Gene expression values (FPKM) were log transformed and $z$-scaled by gene prior to plotting. Visualizations were constructed in $\mathrm{R}$ using the ComplexHeatmap [23] and factoextra (https://github.com/ kassambara/factoextra) packages. A heatmap of genes expressed at FPKM $>1$ on average and significantly upor down-regulated (fold change $>2$ or $<0.5, p<0.05$ ) between aCSF-treated and PLF media-treated MSCs was generated using the Broad Institute's Morpheus tool (https://software.broadinstitute.org/morpheus). Functional annotation analysis was performed using DAVID Bioinformatics Resources 6.8 [24, 25]. Pathway enrichment analysis of MSCs cultured in aCSF and CM was completed using GSEA software (version 4.1.0) [26, 27]. Human_MSigdb_January_13_2021_symbol.gmt and Human_GOALL_no_GO_iea_January_13_2021_symbol.gmt from [http://baderlab.org/Genesets] enabled identification of canonical pathways (hallmark gene sets, BIOCARTA, PID Pathways) and GO gene sets that were enriched in aCSF-treated MSCs [28]. Gene sets with FDR $<0.25$ (canonical pathways) or FDR $<0.1(\mathrm{GO})$ were considered significant.

\section{VEGF ELISA}

To measure the concentration of VEGF protein secreted in vitro from patient adMSCs, cells were again seeded at a density of 3000 cells $/ \mathrm{cm}^{2}$ in triplicate, and the media was changed upon reaching $\sim 80 \%$ confluence to fresh CM, PLF, or aCSF media. The supernatant media was collected and the underlying monolayer was harvested at 24 or $48 \mathrm{~h}$ time points. Media and cell pellets were flash frozen on dry ice and stored at $-80 \mathrm{C}$ for DNA or RNA isolation. VEGF within supernatant media was measured using the Quantikine ELISA kit (R\&D Systems, Minneapolis MN USA) according to the manufacturer's instructions using a two-parameter logistical standard curve. VEGF levels were normalized to total DNA following extraction using DNEasy Blood \& Tissue Kit (Qiagen, Valencia, CA, USA) and nanodrop quantification.

\section{Measurement of analyte concentrations in human CSF}

ALS patients enrolled in a previously completed clinical trial (ClinicalTrials.gov \#NCT01609283) received a dose of autologous adipose-derived MSCs, and CSF was obtained before treatment and 1 week after treatment for analysis [17]. Analytes in CSF were measured in duplicate using commercially available immunoassays from Meso Scale Discovery according to their protocols. Samples were diluted with assay-specific diluents using recommended dilutions for CSF. If no recommendation was provided, the appropriate dilution was determined through linearity of dilution tests. MMP-1 and GDF-15 concentrations were measured with R-PLEX assays using
CSF diluted 1 in 10 or 1 in 50, respectively. MCP- 1 concentrations were measured with singleplex V-PLEX assays using CSF diluted 1 in 16. VEGF, PIGF, and bFGF concentrations were measured using a multiplex VPLEX assay using CSF diluted 1 in 2. Each assay plate contained interplate control samples; interplate coefficient of variations for each assay type ranged from 1.79 to $8.84 \%$. Response values corresponding to the intensity of emitted light upon electrochemical stimulation of the assay plate using the Meso Scale Discovery QUICKPLEX SQ120 were acquired, and analyte concentrations were interpolated using MSD Discovery Workbench software.

\section{Statistical analysis}

GraphPad Prism software was used for statistical analysis. Where appropriate, non-parametric data were analyzed by the Kruskal-Wallis test with Dunn's test to correct for multiple comparisons.

\section{Results \\ MSCs cultured in $100 \%$ human CSF for 24 or $48 \mathrm{~h}$ remain morphologically unchanged}

To analyze the morphological changes of adiposederived MSCs in CSF, all four lines of MSCs were cultured in CM, PLF media, or hCSF for 24 or $48 \mathrm{~h}$. At each time point, cells were stained with DAPI, phalloidin, and MitoTracker Red CMX Ros to image the nucleus, cytoskeleton, and mitochondria distribution. All of the surviving cells in each condition showed a fibroid-like morphology, with cells spread out in flat monolayers (Fig. 1a). Cells displayed branched cytoplasms and intact cytoskeletons. Mitochondrial distribution was normal, with most mitochondria being concentrated around the nuclei and filopodia. Nuclei appeared elliptical and speckled as expected. Overall, we detected no alterations in cellular morphology between cells cultured in each of the three conditions.

\section{MSCs exhibit decreased metabolic activity in PLF media and aCSF}

We cultured the four lines of MSCs in CM, PLF media, or aCSF for 24-96 h to assess cellular proliferation and compare metabolic activity over time. As expected, cells in CM showed a normal increase in cellular activity, denoting a normal proliferation rate (Fig. 1b). In contrast, cells in nutrient-deprived PLF and aCSF showed a progressive decrease in metabolic activity, most likely due to decreased proliferation and viability (Fig. 1c, d). Rates of metabolic activity loss varied between cell lines, and it is unclear whether the cells remaining after $96 \mathrm{~h}$ in aCSF had undergone replication during that time. 

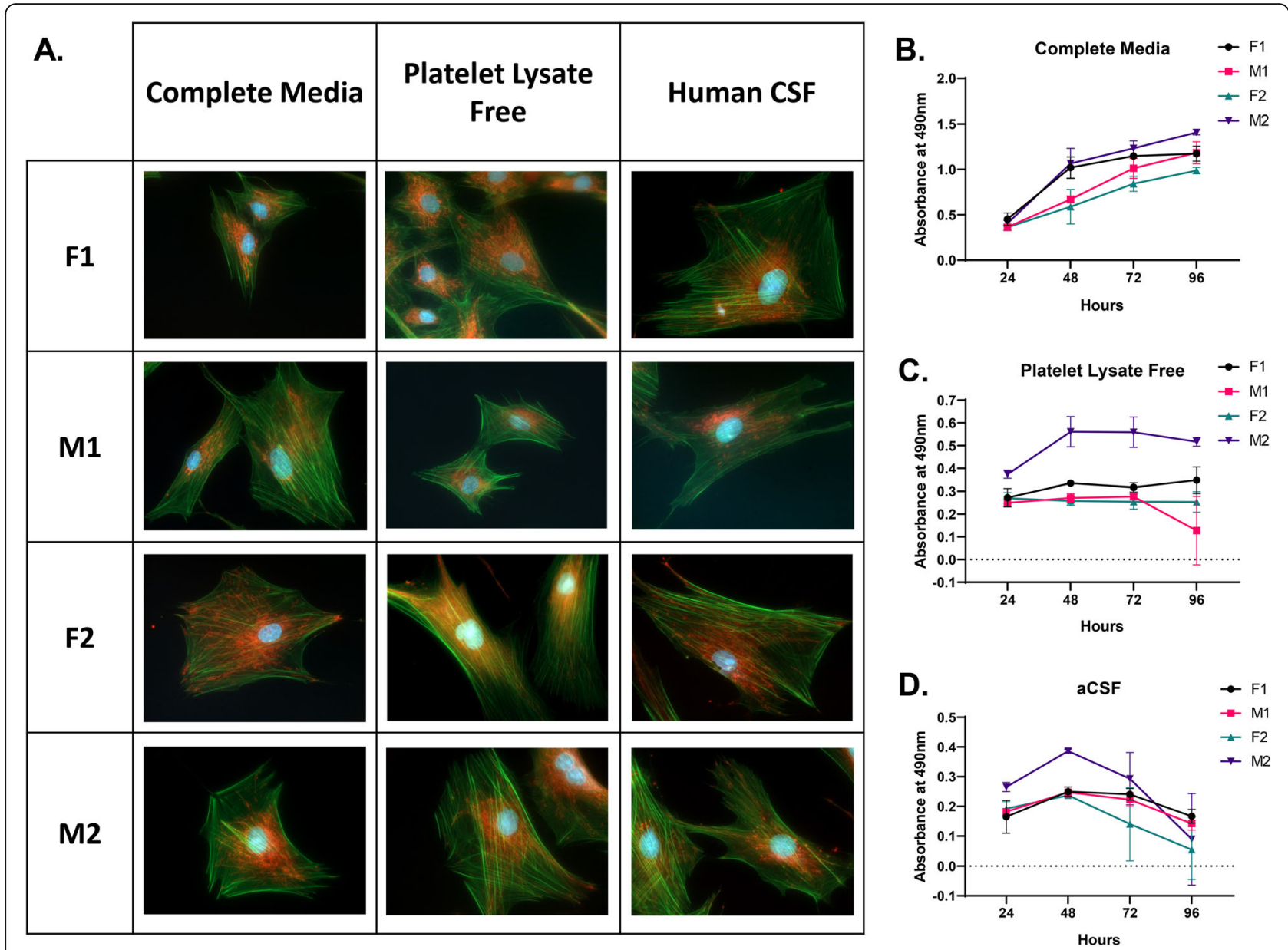

Fig. 1 Morphology and viability of MSCS cultured in CM, PLF media, and human or artificial CSF. a Morphology of MSCs imaged after $24 \mathrm{~h}$ in CM, PLF media, or hCSF. Cells were stained with phalloidin AF488 (green), DAPI (blue), and MitoTracker CMX-Ros (red). Images were taken at 40x magnification. b Metabolic activity of MSCs via MTS assay after 24-96 h in CM. c Metabolic activity of MSCs via MTS assay after 24-96 h in PLF media. d Metabolic activity of MSCs via MTS assay after 24-96 h in aCSF ( $n=3$, mean \pm standard deviation)

\section{Consistent transcriptomic patterns are dependent on culture condition}

To determine how the transcriptomes of MSCs change in response to CSF, we examined gene expression profiles in the four lines of MSCs cultured in CM, PLF media, and aCSF for 24 or $48 \mathrm{~h}$ using high-throughput RNASeq analysis. Unbiased transcriptomic analysis revealed homogeneity of both biological and technical replicates of MSCs cultured in CM, PLF media, or aCSF. Hierarchical clustering produced well-defined clusters of replicates, with the first order of separation being dictated by the treatment group and then by time in each condition (Fig. 2a). Principal components analysis identified culture condition and the time in each condition as accounting for over $50 \%$ of the variability between MSCs cultured in each condition (Fig. 2b). The number of annotated genes mapped from RNA reads totaled 23,398 for all conditions. Of these genes, in all conditions almost half of the genes were expressed at levels greater than 1 FPKM, about $10 \%$ were not appreciably expressed, and almost 50\% were expressed at levels less than 1 FPKM (Fig. 2c).

\section{MSCs cultured in aCSF maintain gene expression of MSC cell surface markers}

MSCs cultured in aCSF express mRNAs for cell surface markers that have been well-defined for MSCs [20, 2931]. Standard cell surface markers for MSCs include CD44, CD73/NT5E, CD90/THY1, CD105/ENG, and MHC class 1 molecules. MSCs cultured in aCSF exhibit robust expression of the genes encoding these markers, albeit at varying levels as compared to cells cultured in CM or PLF media (Fig. 3a). Conversely, MSCs cultured in aCSF demonstrate an absence of expression of genes for hematopoietic, stem cell, or endothelial markers (CD11B, CD14, CD31, CD45, CD253A, HLA-DRA) except for $C D 34$, which was expressed at very low levels (data not shown). 


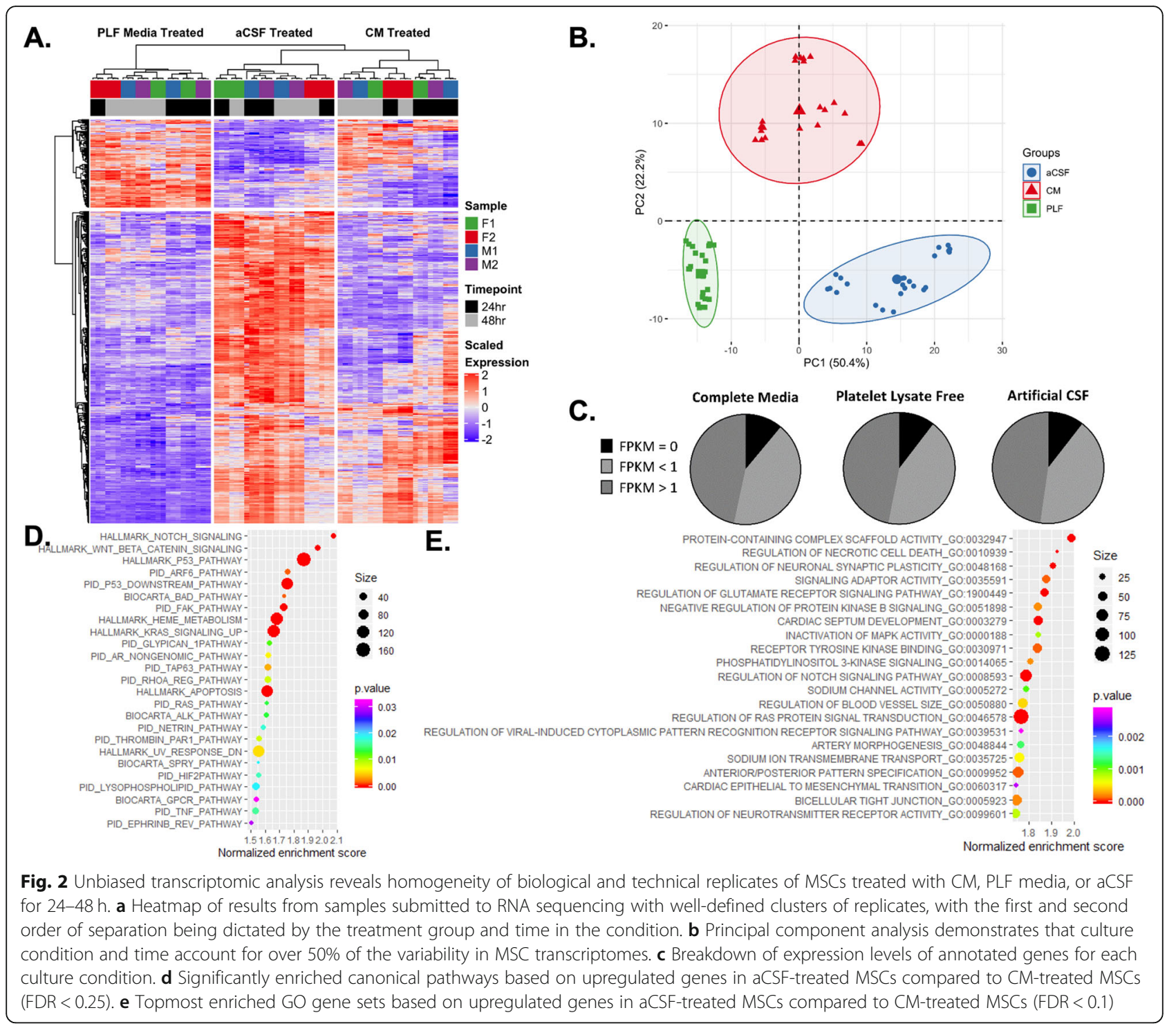

MSCs cultured in aCSF decrease expression of genes involved in proliferation and increase expression of genes involved in promoting the non-canonical Wnt signaling pathway

As recommended by the IFATS/ISCT panel [29], we examined expression of genes encoding factors involved in viability and fibroblastoid colony-forming units (CFU-Fs). As compared to cells in CM, cells cultured in PLF media and aCSF do not exhibit expression of $M K I 67$, which encodes the proliferation marker Ki67, but retain expression of PCNA (Fig. 3b). We also found variable expression of extracellular matrix-associated genes that are reported to be upregulated in post-proliferative cells (COL21A1, MGP, $O G N, P O D N)$, suggesting that cells incubated in aCSF are in a unique post-proliferative state [20] (Fig. 3b).
MSCs cultured in all three conditions expressed mRNAs for genes encoding reprogramming factors (MYC, KLF4, and $K D M 5 B$ ) to varying degrees (Fig. $3 \mathrm{~b}$ ). None of the cells cultured expressed genes for markers of pluripotency (e.g., NANOG, POU5F1, SOX2, LIN28A/B), corroborating previous observations [20,32]. Likewise, assessment of expression of lineage-specific genes revealed low-level expression of few genes for adipogenesis (PPARG), chondrogenesis (SOX9), and osteogenesis (ALPL, RUNX2), with these genes hypothesized to be playing an alternative role in driving matrix mineralization and cell survival in a post-proliferative state (Supp. Figure 1).

Human primary cell quiescence, in addition to being signaled by cell cycle exit, is also promoted by suppression of the canonical Wnt signaling pathway [33]. Notably, cells incubated in aCSF showed marked increases in genes associated with suppressing the canonical Wnt pathway (LRP4, 


\section{Surface Markers for MSCs}

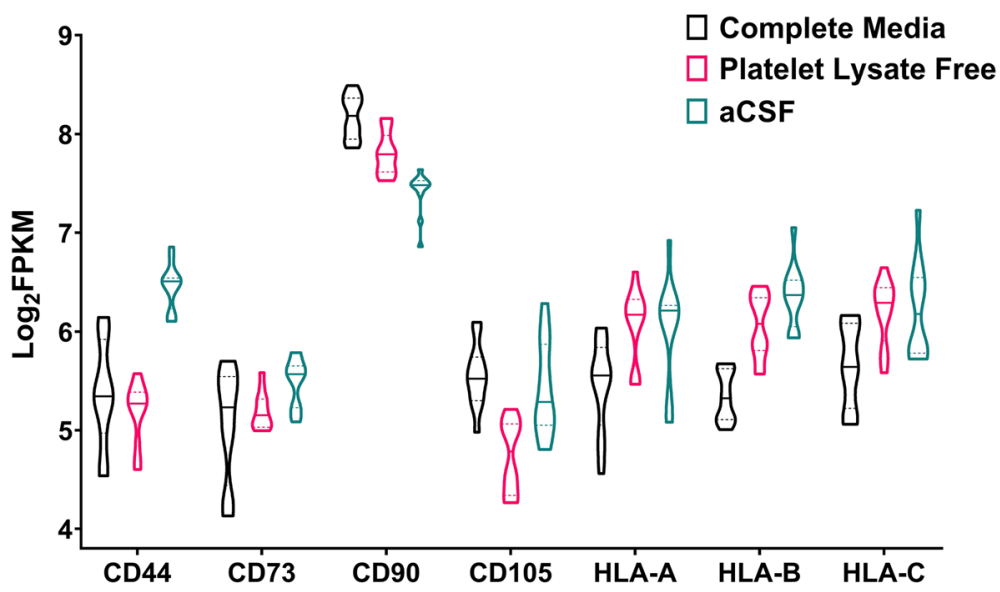

Proliferation and Differentiation Markers

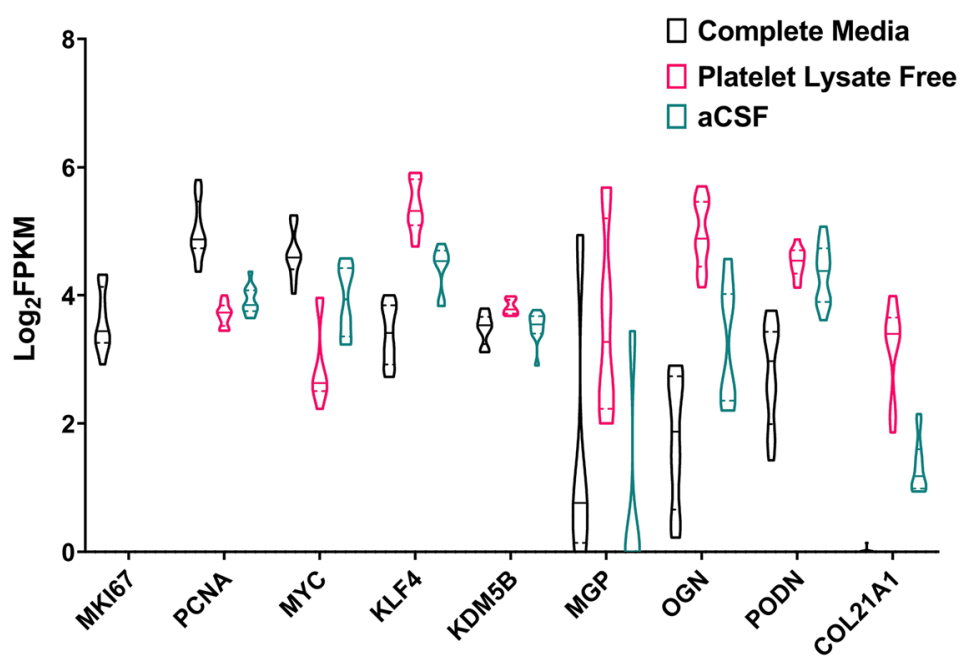

Fig. 3 Expression levels of detectable transcripts of genes encoding characteristic MSC markers by MSCs cultured in CM, PLF, and aCSF. a Detectable expression levels of transcripts encoding surface markers for MSCs $(n=12$, data shown with median and interquartile range). $\mathbf{b}$ Expression levels of transcripts encoding markers of proliferation and differentiation of MSCs. Transcript expression levels are shown as Log 2 FPKM ( $n=12$, data shown with median and interquartile range)

RAPGEF1, AXIN1, DKK1, DKK3, TLE1-4) and a decrease in WNT2 expression (Supp. Fig. 2). Interestingly, aCSFtreated cells retained expression of genes encoding Wnt5A, Wnt5B, Wnt7B, and Wnt9A, which activate the noncanonical Wnt pathway to promote osteoblast differentiation and influence synaptic plasticity, which could impact the regenerative effects of MSCs in the CNS [34, 35].

\section{Expression of genes for secreted factors suggests the} response by MSCs to aCSF is immunomodulatory and enriched for growth factors

It is important to assess changes in the expression of genes encoding secreted factors by MSCs in response to
aCSF. Secreted factors potentially could serve as biomarkers of MSC activity in vivo, and the expression of genes for secreted growth factors specifically have mechanistic relevance to clinical trials that likely depend on the trophic functions of secreted factors.

In examining the expression of immune-related cytokines, we found elevated expression of several factors in aCSFtreated MSCs as compared to PLF media-treated MSCs, including IL6 and CCL2 (encodes MCP-1) to levels comparable to CM-treated cells. MSCs lacked expression of proinflammatory factors. No expression was seen of TNF $\alpha$, $I F N \gamma$, or IL33 in any MSC culture condition, and IL32 was reduced in aCSF (Fig. 4a; non-expressed factors not shown). 
A.

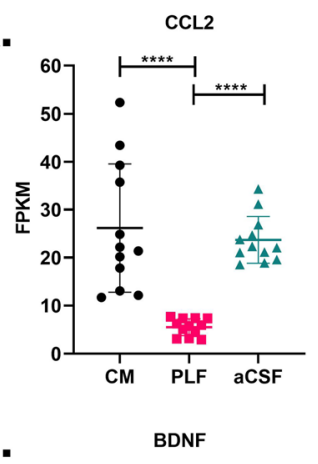

B.
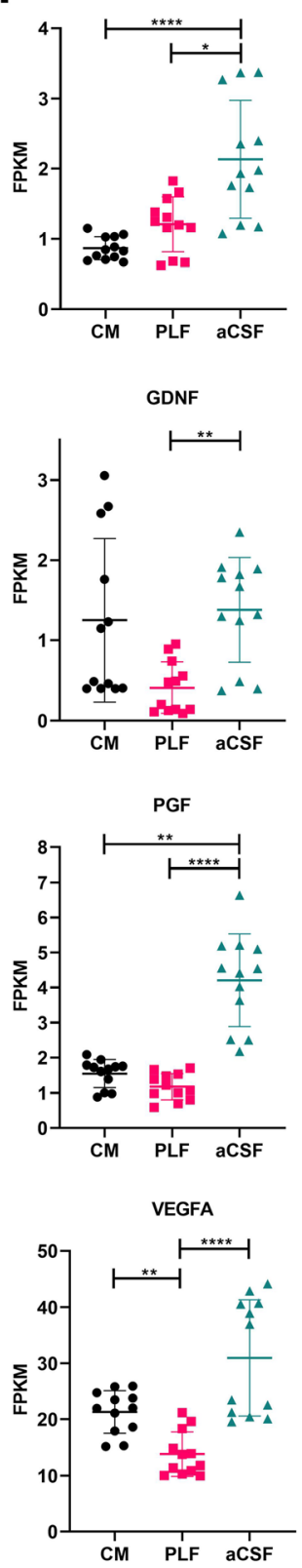
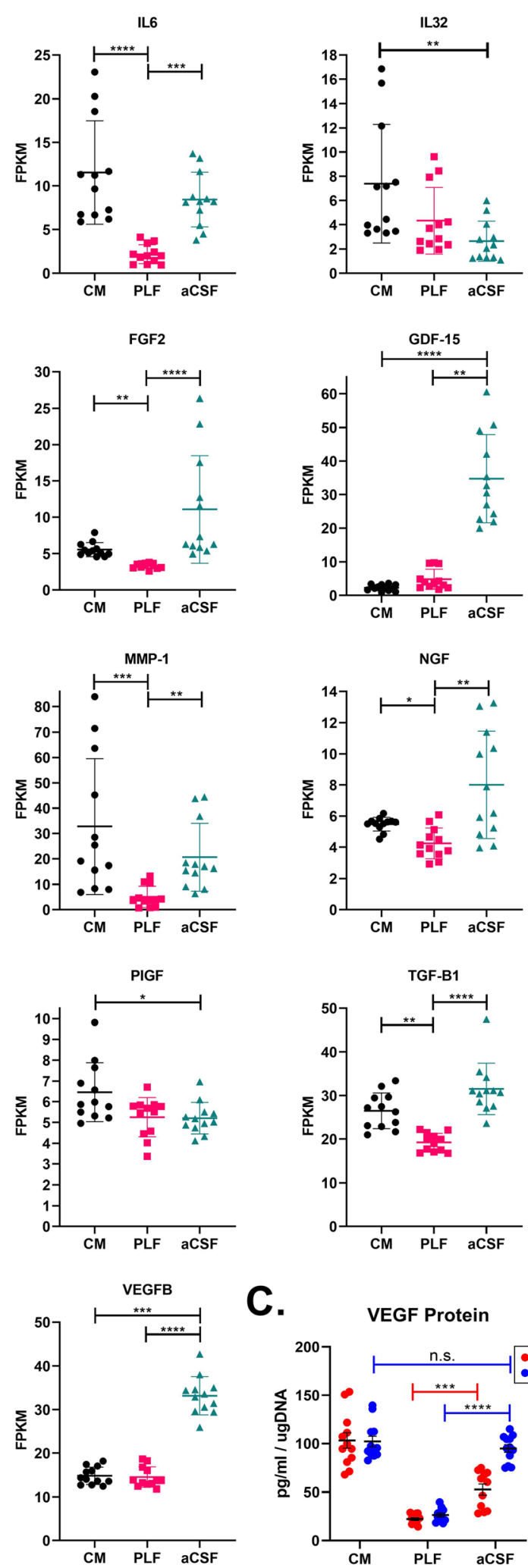

C.

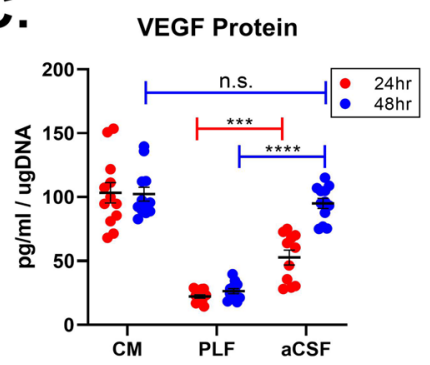


(See figure on previous page.)

Fig. 4 Expression levels of detectable transcripts of genes encoding key immunomodulatory, angiogenic, and neurotrophic factors by MSCs cultured in CM, PLF, and aCSF. a Detectable expression levels (FPKM) of genes encoding immunosuppressive and inflammatory factors $(n=12)$. $\mathbf{b}$ Expression levels (FPKM) of genes encoding select angioneurins and growth factors that are highly expressed by aCSF-treated MSCs $(n=12)$. $\mathbf{c}$ In vitro levels of VEGF protein in MSC cultures in CM, PLF, and aCSF. Data presented with mean \pm standard deviation. The Kruskal-Wallis test with Dunn's test to correct for multiple comparisons were performed to determine statistical significance ${ }^{*}$ indicates $p<0.05$; ** indicates $p<0.01$; *** indicates $p<0.001 ;{ }^{* * *}$ indicates $\left.p<0.0001\right)$

When we looked at the 281 and 392 genes that are significantly upregulated by aCSF-treated MSCs compared with PLF media-treated and CM-treated MSCs, respectively, we identified genes for several growth factors, including BDNF, FGF1, FGF2, GDNF, NGF, PGF, VEGFA, and $V E G F B$ (Fig. 4b). Many of these factors promote angiogenesis, which was identified by functional annotation analysis as a top category of genes up-regulated in aCSF. Several of these factors are identified as angioneurins that have an effect on both angiogenesis and neuroprotection, such as VEGFA, NGF, and FGF [36].

ELISA assays were performed for VEGF on a separate set of MSC cultures exposed to CM, PLF, and aCSF. MSCs exposed to PLF had reduction in VEGF secretion when compared with CM. When exposed to aCSF, there was an initial drop in VEGF secretion at $24 \mathrm{~h}$ in culture, which recovered at $48 \mathrm{~h}$ (Fig. 4c).

\section{CSF growth factor protein levels are increased in humans after intrathecal MSC injection}

To further assess MSC behavior in CSF, protein quantitation was performed on CSF samples from subjects with ALS before and after intrathecal MSC administration. Subjects received an intrathecal dose of $1 \times 10^{7}, 5 \times$ $10^{7}$, or $10 \times 10^{7}$ autologous adipose-derived MSCs. The fold change in protein level comparing the 1 week time point to baseline levels was calculated for each patient and used for statistical analysis. A dose-dependent response trend was observed in VEGF protein levels for each group, with a $1.2 \pm 0.14$ fold change with $1 \times 10^{7}$ MSCs, $3.8 \pm 2.9$ fold change with $5 \times 10^{7}$ MSCs, and a significant $25.3 \pm 18.1$ fold change with $10 \times 10^{7}$ MSCs $\left(p=0.006\right.$; Fig. 5). For PIGF and GDF-15, the $10 \times 10^{7}$ MSC dose again correlates with a significant increase in protein levels compared to the $1 \times 10^{7}$ and $5 \times 10^{7}$ doses ( $p \leq 0.03$ for all; Fig. 5). Statistical analysis demonstrated that the $5 \times 10^{7}$ dose did not correlate with significantly increased growth factor protein expression compared to the $1 \times 10^{7}$ dose for VEGF, PIGF, or GDF-15. There was a trend for dose-dependent increases in MCP-1 and MMP-1, but this did not reach statistical significance. Altogether, high-dose intrathecal MSC injections resulted in increased levels of growth factors in the CNS compartment measured 1 week after treatment.

\section{Discussion}

Our work expands the growing body of knowledge regarding the response characteristics of MSCs to novel stimuli or challenging environmental conditions, which, in turn, informs the use of MSCs in clinical applications [37]. While previous human in vivo studies have provided early evidence of therapeutic benefits in ALS following intrathecal MSC treatment [17, 38, 39], the longterm viability and mechanism of action of MSCs in the CSF environment remain unclear [40-42]. To determine how MSCs fare in the intrathecal space, we conducted a comprehensive investigation of the effects of CSF on human adipose-derived MSCs (manufactured with GMPgrade reagents) that examined changes in morphology, metabolism, and gene expression. Despite no clear gross morphological changes in MSCs cultured in CSF, there was a significant reduction in metabolic activity and a dramatically altered gene expression profile. Transcriptomic analyses revealed that MSCs increase expression of genes for growth factors and immune-modulating factors following culture in CSF. VEGF secretion was likewise maintained in aCSF. Remarkably, the transcriptomic analysis mirrored the protein changes in CSF from subjects with ALS that were treated with intrathecal MSCs.

The unbiased transcriptomic analysis also revealed that MSCs demonstrate a distinct, robust profile of gene expression when cultured in aCSF, PLF media, or CM. MSCs in aCSF and PLF retain the expression of genes encoding cell surface markers and reprogramming factors characteristic of MSCs in CM [20,43], but lack expression of markers of active cellular proliferation. However, mRNA levels for markers of post-proliferative cells were differentially expressed to varying degrees in aCSF-treated MSCs as compared to PLF media-treated and CM-treated cells. The differential expression of Wnt ligands and pathway modulators suggests that aCSFtreated cells are quiescent, yet retain the ability to differentiate and promote synaptic plasticity, in part due to the expression of factors along the non-canonical Wnt pathway and the conserved expression of reprogramming factors $[34,35]$. This expression pattern likely reflects that aCSF-treated MSCs-which decrease proliferation while sustaining trophic factor expressionare in a post-proliferative state that is distinct from that of hPL-deprived MSCs cultured in PLF media or confluent cells in CM. 


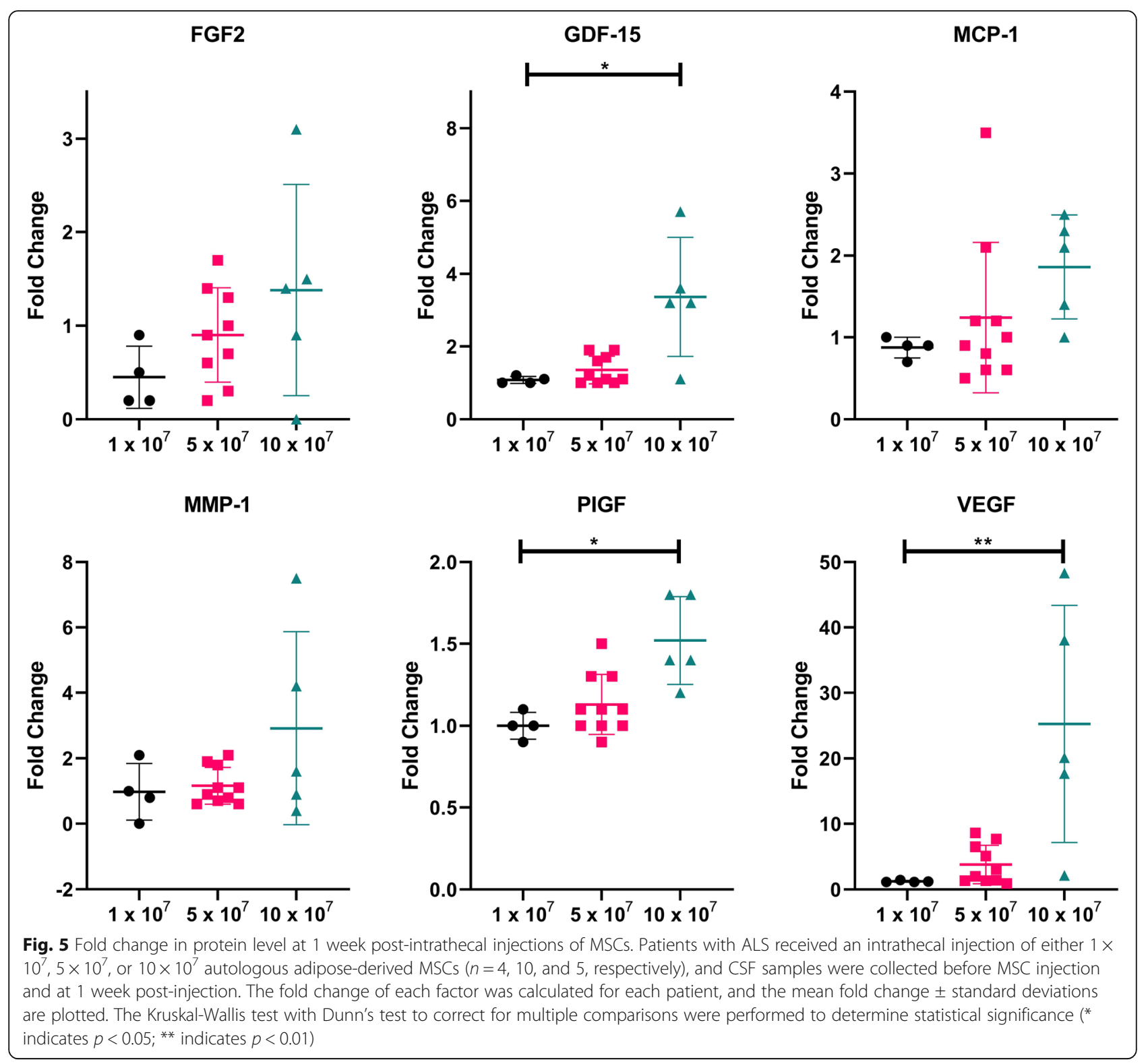

When we examined genes that were significantly upregulated in aCSF compared to PLF media and CM, numerous genes for immune-modulating factors that are expressed at more than twice the levels seen in PLF media were identified. The expression of antiinflammatory factors and lack of expression of proinflammatory genes by MSCs in aCSF suggests that these cells would suppress, rather than promote, inflammation in the CNS, consistent with previous reports suggesting this anti-inflammatory effect is therapeutic in disease models [41, 44]. Immune system abnormalities [45-47] and neuroinflammation [48, 49] are increasingly recognized as contributors to disease pathology in ALS and are being explored as therapeutic targets in clinical trials.
Strikingly, aCSF exposure augmented the expression of angiogenic and growth factor genes over and above expression levels seen in PLF media. Previous studies have reported that human MSCs, even under serum deprivation conditions, are highly angiogenic [50-53], and express growth factors that promote neuroprotection, remyelination, and therapeutic effects in animal models of neurological diseases [54-57]. In support of these prior studies, we found that cells incubated in aCSF express genes for angiogenic and growth factors (e.g., GDNF, MCP-1) at levels seen in CM-treated MSCs. Increased $M C P-1$ and GDNF expression by MSCs delivered intrathecally or intramuscularly into a rat model of ALS has been shown to delay motor function loss and to increase survival $[41,56]$. In addition, this study found 
that aCSF caused expression of several genes for growth factors above the expression levels seen in CM (BDNF, FGF2, NGF, PGF, VEGFA, VEGFB).

This study identified that MSCs upregulate VEGF expression in both in vitro and in vivo conditions, giving insight to the probable mechanism of action of MSCs. Notably, upregulation of VEGF protein can regulate both angiogenesis and neurodegeneration, including degeneration of motoneurons [36]. For instance, studies have found that mice had reduced VEGF levels prior to developing symptoms of spinal and bulbar muscular atrophy and adult-onset motoneuron degeneration that resembled the degeneration seen in ALS $[58,59]$. Conversely, overexpression of VEGF improves motor performance and prolongs survival in rodent models of ALS, particularly when paired with enhanced GDNF expression [60]. Likewise, expression of VEGF promotes neurogenesis and neural stem cell differentiation post-injury [61, 62]. By increasing neural perfusion around sites of neurodegeneration and ischemia, VEGF could promote neuroprotection for surviving motoneurons in the spinal cord and stimulate neuroregeneration. This hypothesis is further supported by the early success of clinical trials using MSCs with enhanced VEGF secretion to treat neurodegenerative disorders $[11,38]$. We measured a dosedependent increase in CSF VEGF in patients with ALS following intrathecal treatment of autologous adipose-derived MSCs. The combination of increased gene expression in in vitro conditions and increased protein levels in in vivo conditions support the claim that MSCs within the intrathecal space produce significant quantities of therapeutic growth factors. Alternatively, MSCs could induce CNS cells to upregulate growth factor production. Regardless of the source of growth factors, their increased quantities confirm that MSCs are exerting therapeutic effects within the CNS compartment. Furthermore, high doses of MSCs $\left(10 \times 10^{7}\right)$ were required to elicit significant increases in protein expression of beneficial growth factors. These data are critical for researchers using MSC-based treatments as there are very few studies comparing MSC doses on therapeutic effect $[16,17]$.

There are now several completed human clinical trials that have utilized intrathecal autologous MSC therapy for ALS [17, 38, 39, 63]. While there are signs of efficacy of MSC treatment in ALS, it is also becoming clear that some patients are more or less likely to respond to this therapy. Understanding this variability in response to MSC therapy will be critical for understanding ALS pathogenesis, MSC therapies, and how best to translate this therapy to clinical practice. Berry et al. reported that higher CSF VEGF was correlated with lower CSF MCP1 in patients treated with modified bone-marrowderived MSCs [38]. They also reported that lower postMSC treatment MCP-1 correlated with better outcomes, which was also seen in Oh et al. [39]. Our phase I study did not have clinical outcomes to correlate with the CSF findings; however, we are now pursuing these hypotheses as part of an active phase II clinical trial of MSCs in ALS (ClinicalTrials \#NCT03268603).

To our knowledge, this is the first reported large-scale transcriptomic analysis of multiple lines of human adipose-derived MSCs exposed to undiluted aCSF or hCSF. Unbiased examination of the differential expression of over 23,000 genes provided the most detailed understanding to date of how the transcriptomic profile of clinical-grade MSCs varies between normal, hPLdeprived, and intrathecal-like culture conditions. By understanding how the response of MSCs to CSF resembles-and is distinct from-the response to CM or PLF media, the field gains an appreciation for the scope of the phenotypic responses of MSCs. We further have shown that intrathecal injection of adipose-derived autologous MSCs in subjects with ALS leads to a dosedependent increase in CSF growth factors. From a therapeutic standpoint, if MSCs respond to individual culture conditions with unique gene expression profiles, then proper preparation of MSCs could impact the secretion of therapeutic factors and biomarkers pertinent to the response of patients to MSC treatment.

\section{Conclusion}

Our results demonstrate that MSCs can remain viable and morphologically normal in CSF. Under intrathecal conditions, the cells will decrease metabolic activity and will alter their gene expression to adapt to the novel environment while maintaining high-level expression of supportive factors that can be measured in the CSF of subjects treated with intrathecal MSCs for ALS. Overall, our results identify potential modes of therapeutic efficacy as well as candidate biomarkers of MSC potency to guide clinical translation of MSC-based therapies for neurodegenerative diseases.

This work validates the continued use MSCs in clinical trials, and also supports using the $10 \times 10^{7}$ dose to maximize therapeutic benefit.

\section{Abbreviations \\ MSC: Mesenchymal stromal cell; CSF: Cerebrospinal fluid; hCSF: Human cerebrospinal fluid; aCSF: Artificial cerebrospinal fluid; ALS: Amyotrophic lateral sclerosis; CNS: Central nervous system; hPL: Human platelet lysate; GMP: Good manufacturing practices; CM: Control media; PLF: Platelet lysate- free; IRB: Institutional Review Board; MEM: Minimal essential medium; PBS: Phosphate buffer solution; PCR: Polymerase chain reaction; FPKM: Fragments per kilobase pair per million mapped reads}

\section{Supplementary Information}

The online version contains supplementary material available at https://doi. org/10.1186/s13287-021-02241-9.

Additional file 1: Supplemental Figure 1. Expression levels of detectable transcripts of lineage-specific genes for adipogenesis, 
chondrogenesis, and osteogenesis. Expression levels of transcripts encoding markers of MSC lineage differentiation $(n=12$, data shown with median and interquartile range).

Additional file 2: Supplemental Figure 2. Expression levels of detectable transcripts of genes associated with the canonical and noncanonical Wnt signaling pathways. Expression levels of transcripts encoding markers of Wnt pathway signaling $(n=12$, data shown with median and interquartile range).

Additional file 3: Supplemental Figure 3. Expression levels of selected genes using real-time $\mathrm{QPCR}$ confirms transcriptonic dataset.

\section{Acknowledgements}

We thank the Mayo Clinic Immune Progenitor and Cell Therapy Lab for processing patient MSCs and providing study material. We thank the staff of the Mayo Clinic Genome Analysis Core and Bioinformatics Core for performing the transcriptomic analyses and preliminary data processing.

\section{Authors' contributions}

Ashley A. Krull, PhD: Conception and design, data acquisition and analysis, data interpretation, manuscript writing. Deborah Setter, MD, PhD: Data analysis, data interpretation, manuscript writing. Tania Gendron, PhD: Data acquisition and analysis, data interpretation, manuscript writing. Sybil C.L. Hrstka, PhD: Data analysis, data interpretation, manuscript writing. Michael J. Polzin: Data acquisition and analysis. Joseph Hart: Data acquisition and analysis, data interpretation. Amel Dudakovic, PhD: Conception and design, data acquisition and analysis, data interpretation. Nicolas N. Madigan M.B., B.Ch., Ph.D.: Data analysis, data interpretation, manuscript writing. Allan B. Dietz, PhD: Data acquisition, manuscript writing. Anthony J. Windebank, MD: Conception and design, data analysis, data interpretation, manuscript writing. Andre J. van Wijnen, PhD: Conception and design, data analysis, data interpretation, manuscript writing. Nathan P. Staff, MD, PhD: Conception and design, data analysis, data interpretation, manuscript writing, final approval of the manuscript. All authors have approved the submitted version of this manuscript. All authors agree to be personally accountable for their contributions to this work.

\section{Funding}

Funding was provided by the Mayo Clinic Center for Regenerative Medicine.

\section{Availability of data and materials}

We will be submitting our transcriptomics data to Gene Expression Omnibus (GEO) in line with the NIH Genomic Data Sharing (GDS) Policy.

\section{Declarations}

\section{Ethics approva}

Human biosamples described in this manuscript were collected under protocols that were reviewed and approved by the Mayo Clinic Institutional Review Board (IRB). Subjects underwent informed consent prior to participating in research studies. Animal research was not employed in the enclosed studies.

\section{Consent for publication}

Not applicable

\section{Competing interests}

The authors indicated no potential conflicts of interest.

\section{Author details}

${ }^{1}$ Department of Neurology, Mayo Clinic, 200 First St. SW, Rochester, MN 55905, USA. ${ }^{2}$ Department of Neuroscience, Mayo Clinic, Jacksonville, FL 32224, USA. ${ }^{3}$ Department of Orthopedic Surgery, Mayo Clinic, Rochester, MN 55905, USA. ${ }^{4}$ Department of Laboratory Medicine and Pathology, Mayo Clinic, Rochester, MN 55905, USA.
Received: 21 August 2020 Accepted: 24 February 2021

Published online: 18 March 2021

\section{References}

1. Akaishi T, Onishi E, Abe M, Toyama H, Ishizawa K, Kumagai M, Kubo R, Nakashima I, Aoki M, Yamauchi M, et al. The human central nervous system discharges carbon dioxide and lactic acid into the cerebrospinal fluid. Fluids Barriers CNS. 2019;16(1):8-14

2. Zhang J, Goodlett DR, Peskind ER, Quinn JF, Zhou Y, Wang Q, Pan C, Yi E, Eng J, Aebersold RH, et al. Quantitative proteomic analysis of age-related changes in human cerebrospinal fluid. Neurobiol Aging. 2005;26(2):207-27.

3. Mitchell RM, Freeman WM, Randazzo WT, Stephens HE, Beard JL, Simmons Z, Connor JR. A CSF biomarker panel for identification of patients with amyotrophic lateral sclerosis. Neurology. 2009;72(1):14-9.

4. Heywood WE, Galimberti D, Bliss E, Sirka E, Paterson RW, Magdalinou NK, Carecchio M, Reid E, Heslegrave A, Fenoglio C, et al. Identification of novel CSF biomarkers for neurodegeneration and their validation by a highthroughput multiplexed targeted proteomic assay. Mol Neurodegener. 2015;10(1):64-79.

5. Kroksveen AC, Opsahl JA, Guldbrandsen A, Myhr KM, Oveland E, Torkildsen $\mathrm{O}$, Berven FS. Cerebrospinal fluid proteomics in multiple sclerosis. Biochim Biophys Acta. 2015;1854(7):746-56.

6. Potier E, Ferreira E, Meunier A, Sedel L, Logeart-Avramoglou D, Petite $H$. Prolonged hypoxia concomitant with serum deprivation induces massive human mesenchymal stem cell death. Tissue Eng. 2007;13(6):1325-31.

7. Crespo-Diaz R, Behfar A, Butler GW, Padley DJ, Sarr MG, Bartunek J, Dietz AB, Terzic A. Platelet lysate consisting of a natural repair proteome supports human mesenchymal stem cell proliferation and chromosomal stability. Cell Transplant. 2011;20(6):797-811.

8. Ueyama $\mathrm{H}$, Horibe $\mathrm{T}$, Hinotsu $\mathrm{S}$, Tanaka $\mathrm{T}$, Inoue $\mathrm{T}$, Urushihara $\mathrm{H}$, Kitagawa A, Kawakami K. Chromosomal variability of human mesenchymal stem cells cultured under hypoxic conditions. J Cell Mol Med. 2012;16(1):72-82.

9. Ohta M, Suzuki Y, Noda T, Ejiri Y, Dezawa M, Kataoka K, Chou H, Ishikawa N, Matsumoto N, Iwashita Y, et al. Bone marrow stromal cells infused into the cerebrospinal fluid promote functional recovery of the injured rat spinal cord with reduced cavity formation. Exp Neurol. 2004;187(2):266-78.

10. Zurita M, Vaquero J. Functional recovery in chronic paraplegia after bone marrow stromal cells transplantation. Neuroreport. 2004;15(7):1105-8.

11. Petrou P, Gothelf $Y$, Argov Z, Gotkine M, Levy YS, Kassis I, Vaknin-Dembinsky A, Ben-Hur T, Offen D, Abramsky O, et al. Safety and clinical effects of Mesenchymal stem cells secreting Neurotrophic factor transplantation in patients with amyotrophic lateral sclerosis: results of phase $1 / 2$ and $2 a$ clinical trials. JAMA Neurol. 2016;73(3):337-44.

12. Oikonomopoulos A, van Deen WK, Manansala A-R, Lacey PN, Tomakili TA, Ziman A, Hommes DW. Optimization of human mesenchymal stem cell manufacturing: the effects of animal/xeno-free media. Sci Rep. 2015;5(1): 16570.

13. Juhl M, Tratwal J, Follin B, Søndergaard RH, Kirchhoff M, Ekblond A, Kastrup J, Haack-Sørensen M. Comparison of clinical grade human platelet lysates for cultivation of mesenchymal stromal cells from bone marrow and adipose tissue. Scand J Clin Lab Invest. 2016;76(2):93-104.

14. Brun J, Abruzzese T, Rolauffs B, Aicher WK, Hart ML. Choice of xenogenicfree expansion media significantly influences the myogenic differentiation potential of human bone marrow-derived mesenchymal stromal cells. Cytotherapy. 2016;18(3):344-59.

15. Becherucci V, Piccini L, Casamassima S, Bisin S, Gori V, Gentile F, Ceccantini R, De Rienzo E, Bindi B, Pavan P, et al. Human platelet lysate in mesenchymal stromal cell expansion according to a GMP grade protocol: a cell factory experience. Stem Cell Res Ther. 2018;9(1):124.

16. Singer $W$, Dietz AB, Zeller AD, Gehrking TL, Schmelzer JD, Schmeichel AM, Gehrking JA, Suarez MD, Sletten DM, Minota Pacheco KV, et al. Intrathecal administration of autologous mesenchymal stem cells in multiple system atrophy. Neurology. 2019;93(1):e77-87.

17. Staff NP, Madigan NN, Morris J, Jentoft M, Sorenson EJ, Butler G, Gastineau D, Dietz A, Windebank AJ. Safety of intrathecal autologous adipose-derived mesenchymal stromal cells in patients with ALS. Neurology. 2016;87(21): 2230-4.

18. Bydon M, Dietz AB, Goncalves S, Moinuddin FM, Alvi MA, Goyal A, Yolcu Y, Hunt CL, Garlanger KL, Del Fabro AS, et al. CELLTOP clinical trial: first report from a phase 1 trial of autologous adipose tissue-derived Mesenchymal 
stem cells in the treatment of paralysis due to traumatic spinal cord injury Mayo Clin Proc. 2020;95(2):406-14.

19. Mader EK, Butler G, Dowdy SC, Mariani A, Knutson KL, Federspiel MJ, Russell SJ, Galanis E, Dietz AB, Peng KW. Optimizing patient derived mesenchymal stem cells as virus carriers for a phase I clinical trial in ovarian cancer. J Transl Med. 2013;11:20-33.

20. Dudakovic A, Camilleri E, Riester SM, Lewallen EA, Kvasha S, Chen X, Radel DJ, Anderson JM, Nair AA, Evans JM, et al. High-resolution molecular validation of self-renewal and spontaneous differentiation in clinical-grade adipose-tissue derived human mesenchymal stem cells. J Cell Biochem. 2014;115(10):1816-28.

21. Kalari KR, Nair AA, Bhavsar JD, O'Brien DR, Davila Jl, Bockol MA, Nie J, Tang $X$, Baheti S, Doughty JB, et al. MAP-RSeq: Mayo analysis pipeline for RNA sequencing. BMC Bioinformatics. 2014;15:224.

22. Trapnell C, Pachter L, Salzberg SL. TopHat: discovering splice junctions with RNA-Seq. Bioinformatics. 2009;25(9):1105-11.

23. Gu Z, Eils R, Schlesner M. Complex heatmaps reveal patterns and correlations in multidimensional genomic data. Bioinformatics. 2016;32(18):2847-9.

24. Huang da W, Sherman BT, Lempicki RA. Systematic and integrative analysis of large gene lists using DAVID bioinformatics resources. Nat Protoc. 2009; 4(1):44-57.

25. Huang da W, Sherman BT, Lempicki RA. Bioinformatics enrichment tools: paths toward the comprehensive functional analysis of large gene lists. Nucleic Acids Res. 2009;37(1):1-13.

26. Subramanian A, Tamayo P, Mootha VK, Mukherjee S, Ebert BL, Gillette MA, Paulovich A, Pomeroy SL, Golub TR, Lander ES, et al. Gene set enrichment analysis: a knowledge-based approach for interpreting genome-wide expression profiles. Proc Natl Acad Sci U S A. 2005;102(43):15545-50.

27. Mootha VK, Lindgren CM, Eriksson KF, Subramanian A, Sihag S, Lehar J, Puigserver P, Carlsson E, Ridderstrale M, Laurila E, et al. PGC-1alpharesponsive genes involved in oxidative phosphorylation are coordinately downregulated in human diabetes. Nat Genet. 2003;34(3):267-73.

28. Reimand J, Isserlin R, Voisin V, Kucera M, Tannus-Lopes C, Rostamianfar A, Wadi L, Meyer M, Wong J, Xu C, et al. Pathway enrichment analysis and visualization of omics data using g:Profiler, GSEA, Cytoscape and EnrichmentMap. Nat Protoc. 2019;14(2):482-517.

29. Bourin P, Bunnell BA, Casteilla L, Dominici M, Katz AJ, March KL, Redl H, Rubin JP, Yoshimura K, Gimble JM. Stromal cells from the adipose tissuederived stromal vascular fraction and culture expanded adipose tissuederived stromal/stem cells: a joint statement of the International Federation for Adipose Therapeutics and Science (IFATS) and the International Society for Cellular Therapy (ISCT). Cytotherapy. 2013;15(6):641-8.

30. Baer PC, Kuçi S, Krause M, Kuçi Z, Zielen S, Geiger H, Bader P, Schubert R. Comprehensive phenotypic characterization of human adipose-derived stromal/stem cells and their subsets by a high throughput technology. Stem Cells Dev. 2013;22(2):330-9.

31. Camilleri ET, Gustafson MP, Dudakovic A, Riester SM, Garces CG, Paradise CR, Takai H, Karperien M, Cool S, Sampen HJ, et al. Identification and validation of multiple cell surface markers of clinical-grade adipose-derived mesenchymal stromal cells as novel release criteria for good manufacturing practice-compliant production. Stem Cell Res Ther. 2016;7(1):107-22.

32. Apostolou E, Hochedlinger K. Chromatin dynamics during cellular reprogramming. Nature. 2013;502(7472):462-71.

33. Ye X, Zerlanko B, Kennedy A, Banumathy G, Zhang R, Adams Peter D. Downregulation of Wnt signaling is a trigger for formation of facultative heterochromatin and onset of cell senescence in primary human cells. Mol Cell. 2007;27(2):183-96.

34. Davis EK, Zou Y, Ghosh A. Wnts acting through canonical and noncanonical signaling pathways exert opposite effects on hippocampal synapse formation. Neural Dev. 2008;3:32.

35. Chen C-M, Orefice LL, Chiu S-L, LeGates TA, Hattar S, Huganir RL, Zhao H, Xu B, Kuruvilla R. Wnt5a is essential for hippocampal dendritic maintenance and spatial learning and memory in adult mice. Proc Natl Acad Sci. 2017; 114(4):E619-28.

36. Zacchigna S, Lambrechts D, Carmeliet P. Neurovascular signalling defects in neurodegeneration. Nat Rev Neurosci. 2008;9:169.

37. Hagmann S, Moradi B, Frank S, Dreher T, Kammerer PW, Richter W, Gotterbarm T. Different culture media affect growth characteristics, surface marker distribution and chondrogenic differentiation of human bone marrow-derived mesenchymal stromal cells. BMC Musculoskelet Disord. 2013;14:223
38. Berry JD, Cudkowicz ME, Windebank AJ, Staff NP, Owegi M, Nicholson K McKenna-Yasek D, Levy YS, Abramov N, Kaspi H, et al. NurOwn, phase 2, randomized, clinical trial in patients with ALS: safety, clinical, and biomarker results. Neurology. 2019;93(24):e2294-305.

39. Oh KW, Noh MY, Kwon MS, Kim HY, Oh SI, Park J, Kim HJ, Ki CS, Kim SH. Repeated intrathecal mesenchymal stem cells for amyotrophic lateral sclerosis. Ann Neurol. 2018;84(3):361-73.

40. Zhao CP, Zhang C, Zhou SN, Xie YM, Wang YH, Huang H, Shang YC, Li WY, Zhou C, Yu MJ, et al. Human mesenchymal stromal cells ameliorate the phenotype of SOD1-G93A ALS mice. Cytotherapy. 2007;9(5):414-26.

41. Forostyak S, Homola A, Turnovcova K, Svitil P, Jendelova P, Sykova E. Intrathecal delivery of mesenchymal stromal cells protects the structure of altered perineuronal nets in SOD1 rats and amends the course of ALS. Stem Cells. 2014;32(12):3163-72.

42. Staff NP, Jones DT, Singer W. Mesenchymal stromal cell therapies for neurodegenerative diseases. Mayo Clin Proc. 2019;94(5):892-905.

43. Dominici M, Le Blanc K, Mueller I, Slaper-Cortenbach I, Marini F, Krause D, Deans R, Keating A, Prockop D, Horwitz E. Minimal criteria for defining multipotent mesenchymal stromal cells. The International Society for Cellular Therapy position statement. Cytotherapy. 2006;8(4):315-7.

44. Boido M, Piras A, Valsecchi V, Spigolon G, Mareschi K, Ferrero I, Vizzini A, Temi S, Mazzini L, Fagioli F, et al. Human mesenchymal stromal cell transplantation modulates neuroinflammatory milieu in a mouse model of amyotrophic lateral sclerosis. Cytotherapy. 2014;16(8):1059-72.

45. Beers DR, Zhao W, Wang J, Zhang X, Wen S, Neal D, Thonhoff JR, Alsuliman AS, Shpall EJ, Rezvani K, et al. ALS patients' regulatory T lymphocytes are dysfunctional, and correlate with disease progression rate and severity. JCl Insight. 2017;2(5):e89530.

46. Gustafson MP, Staff NP, Bornschlegl S, Butler GW, Maas ML, Kazamel M, Zubair A, Gastineau DA, Windebank AJ, Dietz AB. Comprehensive immune profiling reveals substantial immune system alterations in a subset of patients with amyotrophic lateral sclerosis. Plos One. 2017;12(7):e0182002.

47. Murdock BJ, Zhou T, Kashlan SR, Little RJ, Goutman SA, Feldman EL. Correlation of peripheral immunity with rapid amyotrophic lateral sclerosis progression. JAMA Neurol. 2017;74(12):1446-54.

48. Zurcher NR, Loggia ML, Lawson R, Chonde DB, Izquierdo-Garcia D, Yasek JE, Akeju O, Catana C, Rosen BR, Cudkowicz ME, et al. Increased in vivo glial activation in patients with amyotrophic lateral sclerosis: assessed with [(11)C]-PBR28. Neuroimage Clin. 2015;7:409-14.

49. Gille B, De Schaepdryver M, Dedeene L, Goossens J, Claeys KG, Van Den Bosch L, Tournoy J, Van Damme P, Poesen K. Inflammatory markers in cerebrospinal fluid: independent prognostic biomarkers in amyotrophic lateral sclerosis? J Neurol Neurosurg Psychiatry. 2019;90(12):1338-46.

50. Kinnaird T, Stabile E, Burnett MS, Shou M, Lee CW, Barr S, Fuchs S, Epstein SE. Local delivery of marrow-derived stromal cells augments collateral perfusion through paracrine mechanisms. Circulation. 2004;109(12):1543-9.

51. Oskowitz A, McFerrin H, Gutschow M, Carter ML, Pochampally R. Serumdeprived human multipotent mesenchymal stromal cells (MSCs) are highly angiogenic. Stem Cell Res. 2011;6(3):215-25.

52. Chung E, Rytlewski JA, Merchant AG, Dhada KS, Lewis EW, Suggs LJ. Fibrinbased 3D matrices induce angiogenic behavior of adipose-derived stem cells. Acta Biomater. 2015;17:78-88.

53. Jiang-Hu H, Xiao-Ming Y, Yang X, Chun-Cai X, Xi L, Fu-Biao Y, Yong C, Fei-Yue L. Systemic administration of exosomes released from mesenchymal stromal cells attenuates apoptosis, inflammation, and promotes angiogenesis after spinal cord injury in rats. J Neurotrauma. 2017;34(24):3388-96.

54. Ankeny DP, McTigue DM, Jakeman LB. Bone marrow transplants provide tissue protection and directional guidance for axons after contusive spinal cord injury in rats. Exp Neurol. 2004;190(1):17-31.

55. Lu P, Jones LL, Tuszynski MH. BDNF-expressing marrow stromal cells support extensive axonal growth at sites of spinal cord injury. Exp Neurol. 2005;191(2):344-60.

56. Krakora D, Mulcrone P, Meyer M, Lewis C, Bernau K, Gowing G, Zimprich C, Aebischer P, Svendsen CN, Suzuki M. Synergistic effects of GDNF and VEGF on lifespan and disease progression in a familial ALS rat model. Mol Ther. 2013;21(8):1602-10.

57. Cruz-Martinez P, González-Granero S, Molina-Navarro MM, Pacheco-Torres J, García-Verdugo JM, Geijo-Barrientos E, Jones J, Martinez S. Intraventricular injections of mesenchymal stem cells activate endogenous functional remyelination in a chronic demyelinating murine model. Cell Death Dis. 2016;7:e2223-34. 
58. Oosthuyse B, Moons L, Storkebaum E, Beck H, Nuyens D, Brusselmans K,

Dorpe JV, Hellings P, Gorselink M, Heymans S, et al. Deletion of the hypoxiaresponse element in the vascular endothelial growth factor promoter causes motor neuron degeneration. Nat Genet. 2001;28(2):131-8.

59. Lambrechts D, Storkebaum E, Morimoto M, Del-Favero J, Desmet F, Marklund SL, Wyns S, Thijs V, Andersson J, van Marion I. VEGF is a modifier of amyotrophic lateral sclerosis in mice and humans and protects motoneurons against ischemic death. Nat Genet. 2003;34(4):383-94.

60. Storkebaum E, Lambrechts D, Dewerchin M, Moreno-Murciano M-P, Appelmans $\mathrm{S}$, Oh H, Van Damme P, Rutten B, Man WY, De Mol M. Treatment of motoneuron degeneration by intracerebroventricular delivery of VEGF in a rat model of ALS. Nat Neurosci. 2005;8(1):85-92.

61. Sun Y, Jin K, Xie L, Childs J, Mao XO, Logvinova A, Greenberg DA. VEGFinduced neuroprotection, neurogenesis, and angiogenesis after focal cerebral ischemia. J Clin Invest. 2003:111(12):1843-51.

62. Wang $Y$, Jin $K$, Mao XO, Xie L, Banwait S, Marti HH, Greenberg DA. VEGFoverexpressing transgenic mice show enhanced post-ischemic neurogenesis and neuromigration. J Neurosci Res. 2007;85(4):740-7.

63. Mazzini L, Mareschi K, Ferrero I, Miglioretti M, Stecco A, Servo S, Carriero A, Monaco F, Fagioli F. Mesenchymal stromal cell transplantation in amyotrophic lateral sclerosis: a long-term safety study. Cytotherapy. 2012; 14(1):56-60

\section{Publisher's Note}

Springer Nature remains neutral with regard to jurisdictional claims in published maps and institutional affiliations.

Ready to submit your research? Choose BMC and benefit from:

- fast, convenient online submission

- thorough peer review by experienced researchers in your field

- rapid publication on acceptance

- support for research data, including large and complex data types

- gold Open Access which fosters wider collaboration and increased citations

- maximum visibility for your research: over $100 \mathrm{M}$ website views per year

At $\mathrm{BMC}$, research is always in progress.

Learn more biomedcentral.com/submissions 